Ryner Jose C. Carrillo, MD' Nathaniel W. Yang, MD ${ }^{2,3}$ Generoso T. Abes, MD, MPH ${ }^{2,3}$

'Department of Otorhinolaryngology

Philippine General Hospital

University of the Philippines Manila

${ }^{2}$ Department of Otorhinolaryngology College of Medicine - Philippine General Hospital University of the Philippines Manila

3Philippine National Ear Institute National Institutes of Health

University of the Philippines Manila
Correspondence: Ryner Jose C. Carillo, MD Department of Anatomy, College of Medicine University of the Philippines Manila Pedro Gil St. Ermita, Manila 1000 Phone: (632) 5264194

sENTro Head and Neck Medicine and Surgery 414 West East Center, 1336 Taft Ave., Ermita, Manila 1000 Phone: 632) 5244455

E-mail: ryner_c@yahoo.com

Reprints will not be available from the author.

No funding support was received for this study. The authors signed a disclosure that they have no proprietary or financia interest with any organization that may have a direct interest in the subject matter of this manuscript, or in any product used or cited in this study.

Presented at:

1. The 25th Politzer Society Meeting. Seoul, Korea, October 2005 (Poster).

2. Resident's Research Forum, Reserch Information and Dissemination Office, Philippine General Hospital, University of the Philippines Manila November 2005

3. Analytical Research Contest (2nd Place), Philippine Society of Otolaryngology Head and Neck Surgery 49th Annual Convention, Westin Philippine Plaza Hotel, Manila, December 1, 2005.

\section{Relationship of Pure Tone Audiometry and Ossicular Discontinuity in Chronic Suppurative Otitis Media}

\begin{abstract}
Background: Pure tone audiometry is routinely used to determine conductive and sensorineural hearing status. Ossicular discontinuity is usually assessed intra-operatively. If ossicular discontinuity can be predicted by pure tone audiometry, perhaps the operative procedure of choice and prognosis for hearing can also be anticipated.
\end{abstract}

Objective: To determine the predictive value of preoperative pure tone audiometry on the presence of gross ossicular discontinuity in chronic otitis media.

Methods: Records of 205 patients, 7 to 75 years of age undergoing their first operation for chronic otitis media were reviewed. Preoperative audiograms and operative records for tympanomastoidectomy were evaluated. A total of 162 patients meeting inclusion criteria were included in the study.

Likelihood ratios for positive and negative ossicular discontinuity for frequency-specific air-bone gap cut-offs were determined. Multiple logistic regression analysis for pure tone audiometry and operative findings to predict ossicular discontinuity was performed and a model for predicting ossicular discontinuity using logistic regression obtained.

Results and Conclusion: Frequency-specific air bone gap (ABG) cut-off values can predict ossicular discontinuity in chronic suppurative otitis media namely: $<20 \mathrm{~dB} \mathrm{ABG}$ at $500 \mathrm{~Hz}$ predicts absence of ossicular discontinuity while $>50 \mathrm{~dB} \mathrm{ABG}$ at $500 \mathrm{~Hz},>30 \mathrm{~dB} \mathrm{ABG}$ at $2 \mathrm{KHz}$, and $>50 \mathrm{~dB}$ $A B G$ at $4 \mathrm{KHz}$ best predict the presence of ossicular discontinuity in general.

In the absence of cholesteatoma, the air bone gaps of $<30 \mathrm{~dB}$ at $500 \mathrm{~Hz}$ and $<20 \mathrm{~dB}$ at $1 \mathrm{KHz}$ decrease probability of ossicular discontinuity from $32.97 \%$ to $2.54 \%$. Combination of air bone gaps of $>50 \mathrm{~dB}$ at $500 \mathrm{~Hz},>20 \mathrm{~dB}$ at $2 \mathrm{KHz}$ and $>40 \mathrm{~dB}$ at $4 \mathrm{KHz}$ increase the probability of ossicular discontinuity from $32.97 \%$ to $85.9 \%$. These findings suggest that ossicular exploration may not be necessary for the former while an evaluation of the ossicular chain may be mandatory for the latter in the setting where cholesteatoma is not present or suspected.

Presence of cholesteatoma, granulation tissue and size of tympanic membrane perforation are important factors to consider in predicting ossicular discontinuity.

Keywords: air bone gap; audiometry, pure tone; ossicular discontinuity; otitis media, suppurative; logistic regression; likelihood ratio; predictive value.

CHRONIC otitis media is a common ear pathology operated on and a common cause of hearing impairment in the local setting. Chronic infection may lead to middle ear structure changes including ossicular discontinuity. Surgical intervention usually aims to eradicate disease and restore hearing.

Restoration of hearing may be attained in well-planned ear surgery. Hearing tests (Pure Tone Audiometry, Speech Testing) and imaging studies ( $\mathrm{x}$-rays, high resolution computed tomography scanning) are used to predict serviceable hearing reserve and anatomical integrity, 
respectively.

In our setting, pure tone audiometry is a routine preoperative procedure for tympanomastoidectomy while computed tomography is expensive and less widely used. Further, ossicular integrity can be assessed by high-resolution tomography, but can only be confirmed intra-operatively ${ }^{1-5}$. Lacking prior information, patient prognosis and surgical management techniques can only be determined during surgery.

A previous study of the possible predictive value of audiograms on ossicular status showed that the preoperative hearing tests did not correlate with ossicular discontinuity ${ }^{6}$. However, studies of ossicular dysfunction must be frequency-specific since the ossicular chain and tympanic membrane have different efficiencies across frequencies ${ }^{7,8}$.

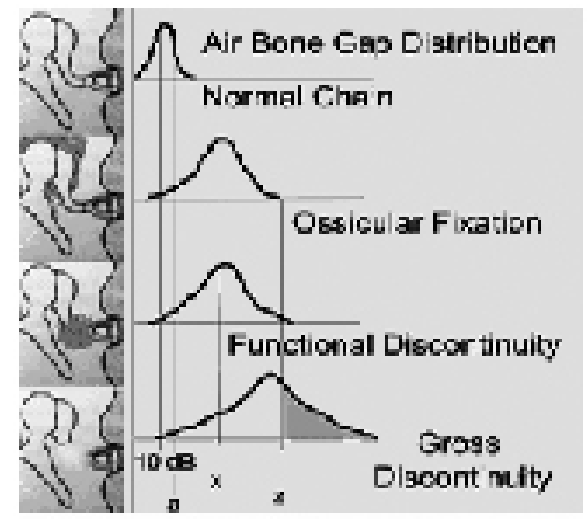

Figure 1. Theoretical Air Bone Gap Distribution

By far, pure tone audiometry is the only routine test to quantitatively assess the hearing capacity of patients with otitis media undergoing surgery ${ }^{9}$. Should this be able to predict ossicular chain status, the conduct and the prognosis of ear surgery may be determined.

Hypothetical air bone gap distributions can be plotted as shown in figure 1. A normal air bone gap will lie between -10 to $15 \mathrm{~dB}$. Varying degrees of ossicular chain dysfunction, i.e., ossicular fixation, functional ossicular discontinuity and gross ossicular discontinuity may be represented by varying degrees of conductive hearing loss represented by the air bone gap.

Being able to determine minimum and maximum cut-off levels that may represent absence or presence of particular ossicular defects will allow a routine audiogram to predict specific defects in the hearing mechanism.

Like the electrocardiogram predicting particular heart defects through "lead-specific tracings", a frequency-specific audiogram may perhaps point to particular hearing deficits.

Correlations between pure tone audiometry and ossicular discontinuity can be modified by the type and degree of tympanic perforation, middle ear polyps, degree and bilaterality of hearing loss. Granulation tissue and cholesteatoma may be independent predictors of ossicular discontinuity but may alter results of hearing by direct
Table 1. Operative Findings

\begin{tabular}{|l|r|r|}
\hline \multicolumn{1}{|c|}{ Frequency } & Percent \\
Gross ossicular discontinuity & $92 / 162$ & $56.8 \%$ \\
Cholesteatoma & $91 / 161$ & $56.2 \%$ \\
Granulation Tissue & $85 / 162$ & $52.5 \%$ \\
Tympanosclerosis & $22 / 162$ & $13.6 \%$ \\
Attic Perforation & $21 / 162$ & $13.4 \%$ \\
Subperiosteal Abscess & $2 / 161$ & $1.2 \%$ \\
Polyp in the middle ear & $9 / 162$ & $5.6 \%$ \\
\hline
\end{tabular}

Table 2. Average of frequency specific air bone gaps

\begin{tabular}{|c|c|c|}
$\begin{array}{c}\text { Frequency } \\
\text { Air bone gap }\end{array}$ & $\begin{array}{c}\text { Mean } \\
\text { Deviation }\end{array}$ & Standard \\
$500 \mathrm{~Hz}$ & 41.17 & 16.81 \\
$1 \mathrm{KHz}$ & 35.77 & 17.34 \\
$2 \mathrm{KHz}$ & 20.56 & 13.76 \\
$4 \mathrm{KHz}$ & 34.17 & 15.30 \\
\hline
\end{tabular}

Table 3. Likelihood Ratios (LR) and changes in Pretest to Post-test Probabilities* $^{*}$

\begin{tabular}{|c|c|c|}
\hline $\begin{array}{l}\text { Likelihood Ratio } \\
\text { for a Positive test }\end{array}$ & $\begin{array}{l}\text { Likelihood Ratio } \\
\text { for a Negative test }\end{array}$ & $\begin{array}{l}\text { Generated Changes in } \\
\text { Pretest to Post-test } \\
\text { Probabilities }\end{array}$ \\
\hline$>10$ & $<0.1$ & Large and conclusive changes \\
\hline $5-10$ & $0.1-0.2$ & Moderate shifts \\
\hline $2-5$ & $0.2-0.5$ & $\begin{array}{l}\text { Small but sometimes important } \\
\text { shifts }\end{array}$ \\
\hline $1-2$ & $0.5-1$ & Rarely important shifts \\
\hline
\end{tabular}

"Evidence Based Medicine Working Group. The Users' Guides to Evidence-based Medicine"

Table 4. Air bone gap (ABG) cut off values at $500 \mathrm{~Hz}$ and corresponding likelihood ratios (LR) for absence or presence of gross ossicular discontinuity (OD).

\begin{tabular}{|c|c|c|c|c|c|}
\hline $\begin{array}{c}A B G \\
500 \mathrm{~Hz}(\mathrm{~dB})\end{array}$ & $\begin{array}{l}\text { OD } \\
(+)\end{array}$ & $\begin{array}{l}\text { OD } \\
(-)\end{array}$ & $\begin{array}{l}\text { LR } \\
(+)\end{array}$ & $\begin{array}{l}\text { LR } \\
(-)\end{array}$ & $\begin{array}{c}P \\
\text { value }\end{array}$ \\
\hline $0-10$ & 2 & 6 & \multirow{8}{*}{$\begin{array}{l}1.070 \\
1.141 \\
1.322 \\
1.443 \\
2.283 \\
1.775 \\
1.522\end{array}$} & \multirow{2}{*}{0.254} & \multirow[b]{2}{*}{0.068} \\
\hline$>10-20$ & 6 & 8 & & & \\
\hline$>20-30$ & 11 & 14 & & 0.435 & 0.033 \\
\hline$>30-40$ & 15 & 13 & & 0.516 & 0.006 \\
\hline$>40-50$ & 25 & 18 & & 0.686 & 0.005 \\
\hline$>50-60$ & 26 & 8 & & 0.761 & 0.003 \\
\hline$>60-70$ & 5 & 2 & & 0.965 & 0.299 \\
\hline$>70$ & 2 & 1 & & 0.992 & 0.602 \\
\hline
\end{tabular}


ORIGINAL ARTICLES

Table 5. Air bone gap (ABG) cut off values at $1 \mathrm{KHz}$ and corresponding likelihood ratios $(\mathrm{LR})$ for absence or presence of gross ossicular discontinuity (OD).

\begin{tabular}{|ccc|c|c|c|}
\hline $\begin{array}{c}\text { ABG } \\
\mathrm{KHz}(\mathrm{dB})\end{array}$ & $\begin{array}{c}\text { OD } \\
(+)\end{array}$ & $\begin{array}{c}\text { OD } \\
(-)\end{array}$ & $\begin{array}{c}\text { LR } \\
(+)\end{array}$ & $\begin{array}{c}\text { LR } \\
(-)\end{array}$ & $\begin{array}{c}\mathbf{P} \\
\text { value }\end{array}$ \\
\hline $0-10$ & 7 & 11 & & & \\
\hline$>10-20$ & 11 & 9 & 1.096 & 0.484 & 0.085 \\
\hline$>20-30$ & 11 & 19 & 1.126 & 0.685 & 0.125 \\
\hline$>30-40$ & 24 & 12 & 1.546 & 0.566 & 0.002 \\
\hline$>40-50$ & 19 & 11 & 1.562 & 0.791 & 0.032 \\
\hline$>50-60$ & 12 & 6 & 1.902 & 0.884 & 0.064 \\
\hline$>60-70$ & 7 & 2 & 3.043 & 0.940 & 0.113 \\
\hline$>70$ & 1 & 0 & 2.290 & 0.991 & 0.568 \\
\hline
\end{tabular}

Table 6. Air bone gap (ABG) cut off values at $2 \mathrm{KHz}$ and corresponding likelihood ratios (LR) for absence or presence of gross ossicular discontinuity (OD).

\begin{tabular}{|c|c|c|c|c|c|}
\hline $\begin{array}{c}\mathrm{ABG} \\
2 \mathrm{~K}(\mathrm{~dB})\end{array}$ & $\begin{array}{l}\text { OD } \\
(+)\end{array}$ & $\begin{array}{l}\text { OD } \\
(-)\end{array}$ & $\begin{array}{l}\text { LR } \\
(+)\end{array}$ & $\begin{array}{l}\text { LR } \\
(-)\end{array}$ & $\begin{array}{c}P \\
\text { value }\end{array}$ \\
\hline $0-10$ & 26 & 27 & \multirow{8}{*}{$\begin{array}{c}1.168 \\
1.674 \\
2.283 \\
3.804 \\
3.817 \\
2.290 \\
\text { cnt }\end{array}$} & \multirow{2}{*}{0.733} & \multirow[b]{2}{*}{0.112} \\
\hline$>10-20$ & 22 & 23 & & & \\
\hline$>20-30$ & 20 & 12 & & 0.730 & 0.010 \\
\hline$>30-40$ & 14 & 6 & & 0.835 & 0.016 \\
\hline$>40-50$ & 8 & 2 & & 0.918 & 0.048 \\
\hline$>50-60$ & 1 & 0 & & 0.980 & 0.321 \\
\hline$>60-70$ & 1 & 0 & & 0.991 & 0.568 \\
\hline$>70$ & 0 & 0 & & cnt & cnt \\
\hline
\end{tabular}

Table 7. Air bone gap ( $A B G$ ) cut off values at $4 \mathrm{KHz}$ and corresponding likelihood ratios (LR) for absence or presence of gross ossicular discontinuity (OD).

\begin{tabular}{|c|c|c|c|c|c|}
\hline $\begin{array}{c}A B G \\
4 \mathrm{KHz}(\mathrm{dB})\end{array}$ & $\begin{array}{l}\text { OD } \\
(+)\end{array}$ & $\begin{array}{l}\text { OD } \\
(-)\end{array}$ & $\begin{array}{l}\text { LR } \\
(+)\end{array}$ & $\begin{array}{l}\text { LR } \\
(-)\end{array}$ & $\begin{array}{c}P \\
\text { value }\end{array}$ \\
\hline $0-10$ & 8 & 6 & \multirow{8}{*}{$\begin{array}{c}0.999 \\
1.141 \\
1.446 \\
2.092 \\
2.435 \\
9.925 \\
\text { cnt }\end{array}$} & \multirow{2}{*}{1.014} & \multirow{2}{*}{0.604} \\
\hline$>10-20$ & 6 & 12 & & & \\
\hline$>20-30$ & 21 & 22 & & 0.592 & 0.072 \\
\hline$>30-40$ & 24 & 18 & & 0.666 & 0.012 \\
\hline$>40-50$ & 17 & 7 & & 0.774 & 0.006 \\
\hline$>50-60$ & 10 & 5 & & 0.890 & 0.043 \\
\hline$>60-70$ & 6 & 0 & & 0.937 & 0.031 \\
\hline$>70$ & 0 & 0 & & cnt & cnt \\
\hline
\end{tabular}

Table 8. Gross ossicular discontinuity (OD) and cholesteatoma

\begin{tabular}{|lcc} 
& $\begin{array}{c}\text { OD } \\
(+)\end{array}$ & $\begin{array}{c}\text { OD } \\
(-)\end{array}$ \\
\hline With Cholesteatoma & 62 & 8 \\
\hline No Cholesteatoma & 30 & 61 \\
\hline
\end{tabular}

Odds ratio of $15.75,(p<0.0001)$ conduction of sound. Inability to isolate a particular ear for testing may alter the correlative process. Hence, patients with masking dilemma, canal obstruction, head trauma, intracranial complications of otitis media were excluded from the study.

The air-bone gap degree and pattern should be able to predict an ossicular chain dysfunction. Such dysfunction can be in the form of ossicular chain fixation or discontinuity. Ossicular discontinuity may be further classified as gross or functional discontinuity. Gross discontinuity is the absence of specific ossicular bones or a disruption in the ossicular joints. Functional discontinuity is the absence of unified ossicular movement on manipulation despite the presence of gross ossicular chain continuity due to fibrosis or granulation tissue. Functional discontinuity and ossicular fixation were not analyzed in this study.

This study aims to determine the ability of pure tone audiometry in predicting ossicular discontinuity in chronic suppurative otitis media.

\section{MATERIALS AND METHODS}

Records of 205 patients, 7 to 75 years of age whose first tympanomastoidectomy was performed by a single surgeon (GTA) at the Philippine General Hospital or Manila Doctors Hospital from June 1987 to July 2004 were reviewed. Preoperative audiograms within 12 months of surgery and operative records were analyzed.

Minimum mastoidectomy had to include an atticotomy with visualization of the incudo-stapedial joint. Patients with masking dilemma, obstructed canal lumen less than $3 \mathrm{~mm}$, congenital defects or fractures of the temporal bone and ears with otitis media complications were excluded. All patients were evaluated intraoperatively by the same surgeon through direct ossicular chain visualization with an operative microscope, and by palpation of the ossicular chain. Incudostapedial joint continuity and pathology (granulation or fibrosis) over the ossicular chain were visualized. The malleus handle and incudostapedial joint were palpated further to assess chain continuity. Gross ossicular discontinuity was defined as visualization of a disconnected or absent part of the ossicular chain. Other forms of dysfunction (ossicular fixation and functional dysfunction) were not included in this study.

Other findings including the size and location of tympanic perforation, subperiosteal abscess, tympanosclerosis, cholesteatoma and granulation tissue were tabulated.

Frequency-specific air bone gap cut off values were associated with presence or absence of ossicular discontinuity with significance determined using likelihood ratios (LR) and chi square test/Fisher's exact test.

Univariate analysis of independent factors and possible modifiers predicting ossicular discontinuity was performed. The full model variables (ossicular discontinuity (OD) associated with cholesteatoma, granulation tissue, foul smelling discharge, aural polyp, size and type of perforation, subperiosteal abscess, tympanosclerosis, bilaterality and type of hearing loss, and frequency-specific air bone gap levels) were subjected to the stepwise backward method for model estimation (Wald Test) and Likelihood Ratio Tests in order to arrive at a parsimonious 
model.

Data were encoded using Epi Info 6.04d (Centers for Disease Control, USA and World Health Organization), transformed to STATA file using Stat transfer version 5 (Circle Systems, Inc, USA) and analyzed using Intercooled Stata version 6 (Stata Corporation, USA) and EBMCAL v1.2 (Evidence Based Medicine Calculator).

\section{RESULTS}

Of the 162 patients included in the study, 92 (56.8\%) had gross ossicular discontinuity, 91 (56.2\%) and 85 (52.5\%) had cholesteatoma and granulation tissue respectively. Other operative findings are summarized in Table 1.

Audiometry revealed 112 (69\%) had bilateral hearing loss while 115 (71\%) had mixed hearing loss. Averages of frequency-specific air bone gaps were narrowest at $2 \mathrm{KHz}$ and widest at $500 \mathrm{~Hz}$. (Table 2)

Frequency-specific cut-off values were analyzed for the presence or absence of gross ossicular discontinuity. Corresponding $p$ values were taken using either chi square or Fisher's exact test, and respective likelihood ratios for positive or negative results were obtained. Significant likelihood ratios (LR) were defined as small, moderate or large results. (Table 3 )

For an air bone gap $(A B G)<20 \mathrm{~dB}$ at $500 \mathrm{~Hz}$ the probability of ossicular discontinuity of $56.8 \%$ decreased to $36.4 \%$, predicting absence of gross ossicular discontinuity (OD). For an $A B G>50 \mathrm{~dB}$ at $500 \mathrm{~Hz}$ there were increased chances from $56.8 \%$ to $75 \%$ of predicting the presence of gross ossicular discontinuity. (Table 4)

Air bone gaps $>30 \mathrm{~dB}$ and $>40 \mathrm{~dB}$ generated statistically significant but small effects on the chance of having ossicular chain discontinuity. (Table 5)

Air bone gaps $>30 \mathrm{~dB}$ or $>40 \mathrm{~dB}$ at $2 \mathrm{KHz}$ shifted the baseline probability of OD from $56.8 \%$ to $75 \%$ and $83.34 \%$, respectively. (Table 6)

Air bone gaps $>50 \mathrm{~dB}$ at $4 \mathrm{KHz}$ increased the chance of OD from $56.8 \%$ to $76.2 \%$. Increasing air bone gap cut-off values showed progressive increase in likelihood ratios for a positive test. (Table 7)

Combinations of air bone gaps of $>50 \mathrm{~dB}$ at $500 \mathrm{~Hz},>30 \mathrm{~dB}$ at $2 \mathrm{KHz}$ and $>50 \mathrm{~dB}$ at $4 \mathrm{KHz}$ increased the probability of ossicular discontinuity from a baseline probability of $56.8 \%$ to $94.35 \%$.

There was no significant predictive value for air bone gap levels on the status of ossicular chain continuity in the cholesteatoma group. Cholesteatoma was associated with ossicular discontinuity with an odds ratio of $15.75(p<0.0001)$. (Table 8 )

Among subjects without cholesteatoma, significant cut-off values
Figure 2. Air bone gap and ossicular discontinuity, with or without cholesteatoma

Figure 3. No Cholesteatoma Group: Air bone gap and ossicular discontinuity

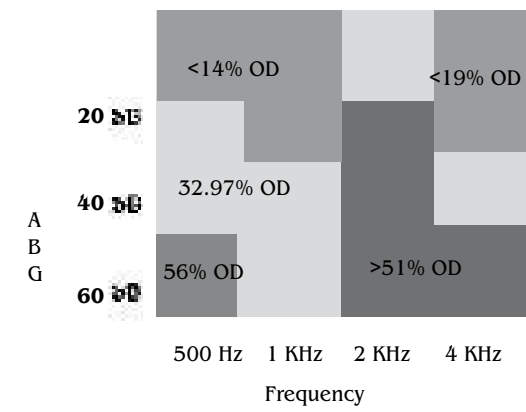

Table 9. No Cholesteatoma Group: Air bone gap (ABG) cut off values at 500 $\mathrm{Hz}$ and corresponding likelihood ratios (LR) for absence or presence of gross ossicular discontinuity (OD).

\begin{tabular}{|c|c|c|c|c|c|}
\hline $\begin{array}{c}A B G \\
500 \mathrm{~Hz}(\mathrm{~dB})\end{array}$ & $\begin{array}{l}O D \\
(+)\end{array}$ & $\begin{array}{l}\text { OD } \\
(-)\end{array}$ & $\begin{array}{l}\text { LR } \\
(+)\end{array}$ & $\begin{array}{l}\text { LR } \\
(-)\end{array}$ & $\begin{array}{c}P \\
\text { value }\end{array}$ \\
\hline $0-10$ & 1 & 5 & \multirow{8}{*}{$\begin{array}{l}1.053 \\
1.228 \\
1.510 \\
1.564 \\
2.588 \\
1.356 \\
2.033\end{array}$} & \multirow{3}{*}{$\begin{array}{l}0.407 \\
0.156\end{array}$} & \multirow{2}{*}{0.351} \\
\hline$>10-20$ & 0 & 8 & & & \\
\hline$>20-30$ & 3 & 13 & & & 0.021 \\
\hline$>30-40$ & 6 & 9 & & 0.313 & 0.004 \\
\hline$>40-50$ & 6 & 15 & & 0.581 & 0.026 \\
\hline$>50-60$ & 12 & 8 & & 0.651 & 0.005 \\
\hline$>60-70$ & 1 & 2 & & 0.982 & 0.535 \\
\hline$>70$ & 1 & 1 & & 0.983 & 0.553 \\
\hline
\end{tabular}

Table 10. No Cholesteatoma Group. Air bone gap (ABG) cut off values at 1 $\mathrm{KHz}$ and corresponding likelihood ratios (LR) for absence or presence of gross ossicular discontinuity (OD).

\begin{tabular}{|c|c|c|c|c|c|}
\hline $\begin{array}{c}\mathrm{ABG} \\
1 \mathrm{KHz}(\mathrm{dB})\end{array}$ & $\begin{array}{l}\text { OD } \\
(+)\end{array}$ & $\begin{array}{l}\text { OD } \\
(-)\end{array}$ & $\begin{array}{l}\text { LR } \\
(+)\end{array}$ & $\begin{array}{l}\text { LR } \\
(-)\end{array}$ & $\begin{array}{c}P \\
\text { value }\end{array}$ \\
\hline $0-10$ & 1 & 10 & \multirow{8}{*}{$\begin{array}{c}1.156 \\
1.277 \\
1.871 \\
1.779 \\
2.287 \\
3.050\end{array}$} & \multirow{3}{*}{$\begin{array}{l}0.203 \\
0.339\end{array}$} & \multirow{2}{*}{0.066} \\
\hline$>10-20$ & 2 & 8 & & & \\
\hline$>20-30$ & 4 & 18 & & & 0.031 \\
\hline$>30-40$ & 9 & 9 & & 0.395 & 0.001 \\
\hline$>40-50$ & 5 & 8 & & 0.723 & 0.044 \\
\hline$>50-60$ & 6 & 6 & & 0.806 & 0.051 \\
\hline$>60-70$ & 3 & 2 & & 0.931 & 0.199 \\
\hline$>70$ & 0 & 0 & & - & - \\
\hline
\end{tabular}


Table 11. No Cholesteatoma Group. Air bone gap (ABG) cut off values at 2 $\mathrm{KHz}$ and corresponding likelihood ratios $(\mathrm{LR})$ for absence or presence of gross ossicular discontinuity (OD).

\begin{tabular}{|c|c|c|c|c|c|}
\hline $\begin{array}{c}A B G \\
2 \mathrm{KHz}(\mathrm{dB})\end{array}$ & $\begin{array}{l}\text { OD } \\
(+)\end{array}$ & $\begin{array}{l}\text { OD } \\
(-)\end{array}$ & $\begin{array}{l}\text { LR } \\
(+)\end{array}$ & $\begin{array}{l}\underset{(-)}{\mathrm{LR}} \\
\end{array}$ & $\begin{array}{c}P \\
\text { value }\end{array}$ \\
\hline $0-10$ & 9 & 24 & \multirow{8}{*}{$\begin{array}{c}1.154 \\
2.153 \\
2.372 \\
2.033 \\
6.00 \\
6.00\end{array}$} & \multirow{3}{*}{$\begin{array}{l}0.763 \\
0.555\end{array}$} & \multirow{2}{*}{0.263} \\
\hline$>10-20$ & 3 & 20 & & & \\
\hline$>20-30$ & 11 & 11 & & & 0.003 \\
\hline$>30-40$ & 5 & 4 & & 0.850 & 0.082 \\
\hline$>40-50$ & 1 & 2 & & 0.965 & 0.401 \\
\hline$>50-60$ & 0 & 0 & & 0.959 & 0.330 \\
\hline$>60-70$ & 1 & 0 & & 0.959 & 0.330 \\
\hline$>70$ & 0 & 0 & & - & - \\
\hline
\end{tabular}

Table 12. No Cholesteatoma Group. Air bone gap (ABG) cut off values at 4 $\mathrm{KHz}$ and corresponding likelihood ratios (LR) for absence or presence of gross ossicular discontinuity (OD).

\begin{tabular}{|c|c|c|c|c|c|}
\hline $\begin{array}{c}A B G \\
4 \mathrm{KHz}(\mathrm{dB})\end{array}$ & $\begin{array}{l}\text { OD } \\
(+)\end{array}$ & $\begin{array}{l}\text { OD } \\
(-)\end{array}$ & $\begin{array}{l}\text { LR } \\
(+)\end{array}$ & $\begin{array}{l}\underset{(-)}{\operatorname{LR}} \\
\end{array}$ & $\begin{array}{c}P \\
\text { value }\end{array}$ \\
\hline $0-10$ & 2 & 5 & \multirow{8}{*}{$\begin{array}{c}1.017 \\
1.238 \\
1.657 \\
2.218 \\
1.627 \\
- \\
-\end{array}$} & \multirow{3}{*}{$\begin{array}{l}0.813 \\
0.271\end{array}$} & \multirow{2}{*}{0.579} \\
\hline$>10-20$ & 0 & 10 & & & \\
\hline$>20-30$ & 6 & 19 & & & 0.032 \\
\hline$>30-40$ & 10 & 16 & & 0.478 & 0.008 \\
\hline$>40-50$ & 8 & 6 & & 0.732 & 0.024 \\
\hline$>50-60$ & 4 & 5 & & 0.944 & 0.335 \\
\hline$>60-70$ & 0 & 0 & & - & - \\
\hline$>70$ & 0 & 0 & & - & - \\
\hline
\end{tabular}

Table 13. Final Model for Patients showing important variables after logistic regression analysis:

\begin{tabular}{lcc} 
& Coefficient & $\begin{array}{c}\text { P } \\
\text { value }\end{array}$ \\
Cholesteatoma & 1.66 & 0.016 \\
Granulation & 2.07 & 0.000 \\
Air bone gap 1 KHz & .032 & 0.037 \\
Size of perforation & .028 & 0.048 \\
_constant & -4.39 & 0.001 \\
\hline
\end{tabular}

were obtained. Air bone gaps $<30 \mathrm{~dB}$ at $500 \mathrm{~Hz}$ decreased the probability of ossicular discontinuity from $32.97 \%$ to $7.67 \%$ while air bone gaps $>$ $50 \mathrm{~dB}$ at $500 \mathrm{~Hz}$ increased the probability of ossicular discontinuity from $32.97 \%$ to $56 \%$. (Table 10 )

In the absence of cholesteatoma, $\mathrm{ABG}<20 \mathrm{~dB}$ at $1 \mathrm{KHz}$ decreased probability of ossicular discontinuity from $32.97 \%$ to $14.29 \%$. (Table 10)

In the no cholesteatoma group, $\mathrm{ABG}>20 \mathrm{~dB}$ at $2 \mathrm{KHz}$ increased the probability of ossicular discontinuity from $32.97 \%$ to $51.4 \%$. (Table 11)

In absence of cholesteatoma, $\mathrm{ABG}>40 \mathrm{~dB}$ at $4 \mathrm{KHz}$ increased the probability of gross ossicular discontinuity from $32.97 \%$ to $52 \%$. (Table 12)

In the no cholesteatoma group, a combination of air bone gaps of $<30 \mathrm{~dB}$ at $500 \mathrm{~Hz}$ and $<20 \mathrm{~dB}$ at $1 \mathrm{KHz}$ decreased probability of ossicular discontinuity from $32.97 \%$ to $2.54 \%$. Combination of air bone gaps of $>50 \mathrm{~dB}$ at $500 \mathrm{~Hz},>20 \mathrm{~dB}$ at $2 \mathrm{KHz}$ and $>40 \mathrm{~dB}$ at $4 \mathrm{KHz}$ increased probability from $32.97 \%$ to $85.9 \%$.

Air bone gap cut off levels were plotted with frequency and probability of ossicular discontinuity. (Figure 2 and Figure 3). The baseline chance of ossicular discontinuity in general was $57 \%$. In the absence of cholesteatoma, the chance of ossicular discontinuity was $33 \%$.

Multiple logistic regression analysis was done using gross ossicular discontinuity as dependent variable. The most parsimonious model consisted of cholesteatoma, granulation, ABG at $1 \mathrm{KHz}$ and size of perforation as the most important independent variables. The simplest model may be used for predicting ossicular discontinuity and the baseline chance of ossicular chain discontinuity was only applicable in this population. (Table 13)

1

Probability of $\mathrm{OD}=$

$1+\mathrm{e}^{-(-4.386+1.66(\text { Cholesteatoma })+2.07 \text { (Granulation) }+0.032(\mathrm{ABG} \text { at } 1 \mathrm{KHZ})+0.0278(\text { Size of Perforation }))}$

Cholesteatoma (0-absent, 1-present)

Granulation (0-absent, 1-present)

$A B G$ at $1 \mathrm{KHz}$ (continuous variable, $0-60$ )

Size of Perforation (continuous variable, $0-100$ )

\section{DISCUSSION}

Frequency-specific air-bone gap (ABG) cut-off values can predict ossicular discontinuity in chronic suppurative otitis media. Generally, $A B G<20 \mathrm{~dB}$ at $500 \mathrm{~Hz}$ predict absence of ossicular discontinuity while $A B G>50 \mathrm{~dB}$ at $500 \mathrm{~Hz},>30 \mathrm{~dB}$ at $2 \mathrm{KHz}$, and $>50 \mathrm{~dB}$ at $4 \mathrm{KHz}$ best predict the presence of ossicular discontinuity in general.

Pre-operative audiograms best detect the absence or presence of ossicular chain discontinuity in the absence of cholesteatoma. 
Likelihood-ratio analysis showed cut-off values in air-bone gaps at $500 \mathrm{~Hz}, 2 \mathrm{KHz}$ and $4 \mathrm{KHz}$ are more reliable determinants of ossicular status. In the absence of cholesteatoma, air-bone gaps of $<30 \mathrm{~dB}$ at $500 \mathrm{~Hz}$ and $<20 \mathrm{~dB}$ at $1 \mathrm{KHz}$ decrease the probability of ossicular discontinuity from $32.97 \%$ to $2.54 \%$. Air-bone gaps of $>50 \mathrm{~dB}$ at 500 $\mathrm{Hz},>20 \mathrm{~dB}$ at $2 \mathrm{KHz}$ and $>40 \mathrm{~dB}$ at $4 \mathrm{KHz}$ increase the probability of ossicular discontinuity from $32.97 \%$ to $85.9 \%$. These findings suggest that ossicular exploration may not be necessary for the former while an evaluation of the ossicular chain may be mandatory for the latter in the setting where cholesteatoma is not present or suspected.

Patterns suggesting an intact ossicular chain dictate a more conservative procedure, e.g., Wullstein type I tympanoplasty while air-bone gap levels that suggest discontinuity warrant thorough inspection and possible reconstruction of the ossicular chain. Routine mastoidectomy for simple tympanic perforations may be avoided, although it may have its advantages ${ }^{12}$.

The presence of cholesteatoma, granulation tissue and size of tympanic membrane perforation are important factors to consider in predicting ossicular discontinuity. The prevalence of ossicular discontinuity and cholesteatoma in this population was $56.8 \%$ and $58.2 \%$, respectively. Cholesteatoma presence is an important risk factor for ossicular chain discontinuity (odds ratio of 15.75) and may warrant ossicular exploration with even simple or small tympanic perforations. The poor correlation of audiograms in this study with ossicular chain discontinuity in the presence of cholesteatoma may be due to the latter's ability to transmit sound. Even with an intact ossicular chain, subjects with cholesteatoma merit mandatory ossicular inspection by atticotomy and/or mastoidectomy with posterior tympanotomy, followed by ossiculoplasty as needed. For such cases, the advantage of Wullstein type III tympanoplasty over type I has been cited in previous studies $^{13}$.

Although ossicular evaluation is routinely performed intraoperatively, prior knowledge of ossicular chain status gleaned from audiograms may influence the planned surgical technique (simple tympanoplasty, atticotomy with attic wall reconstruction, mastoidectomy with posterior tympanotomy and an ossiculoplasty) and implications of treatment, complementing computed tomography (or, as in our setting, replacing it).

Averaging results across frequencies may dilute the predictive value of audiometry on ossicular chain dysfunction. Frequency-specific airbone gap cut-off values can predict gross ossicular discontinuity and the true magnitude of this relationship can be better established in a prospective study. Moreover, varying degrees of ossicular dysfunction may be investigated.
REFERENCES:

1. Banerjee $A$,et al. Computed tomography in suppurative ear disease: does it influence management? J Laryngol Otol. 2003 Jun;117(6):454-8.

2. Fuse T, et al. Diagnosis of ossicular chain in the middle ear by high-resolution CT. Nippon Jibiinkoka Gakkai Kaiho. 1992 Feb;95(2):247-52.

3. Jackler, RK, et al. Computed tomography in suppurative ear disease: a correlation of surgical and radiographic findings. Laryngoscope. 1984 Jun;94(6):746-52

4. Leighton $\mathrm{SE}$, et al. The role of $\mathrm{CT}$ imaging in the management of chronic suppurative otitis media Clin Otolaryngol. 1993 Feb;18(1):23-9.

5. Swartz, J, et al. Ossicular erosions in the dry ear: CT diagnosis. Radiology. 1987 Jun;163(3):763-5.

6. Jeng Fuh-Cheng, et al. Relationship of Preoperative Findings and Ossicular Discontinuity in Chronic Otitis Media. Otology and Neurotology. Vol. 24, No. 3, 2003.

7. Cummings, CW, et al. Otolaryngology Head and Neck Surgery. 3rd Edition. 1998

8. Ruckenstien, M. Comprehensive Review of Otolaryngology. 2004

9. PSO-HNS Clinical Practice Guideline on Chronic Suppurative Otitis Media, 1986.

10. Karja J, et al. Destruction of ossicles in chronic otitis media. J Laryngol Otol. 1976 Jun;90(6):50918.

11. Roman Jaeschke, Gordon H. Guyatt, David L. Sackett, and the Evidence Based Medicine Working Group. The Users' Guides to Evidence-based Medicine and reproduced with permission from JAMA. (1994;271(5):389-391) and (1994;271(9):703-707). Copyright 1995, American Medical Association.

12. McGrew, BM., et al. Impact of mastoidectomy on simple tympanic membrane perforation repair. The Laryngoscope. 2004; 114: 506-511.

13. Sakagami, M. et al. Cholesteatoma otitis media with intact ossicular chain. Auris Nasus Larynx. 1999: (26) 147-151. 